\section{Advanced Metallographic Techniques Applied to Diesel Particulate Filters}

Natalio Saenz, Heather Dillon, Shelley Carlson, \& Gary Maupin

Battelle PNNL, Richland, WA

nt.saenz@pnl.gov

\section{Project Overview}

Diesel Particulate Filters (DPFs) are designed to capture exhaust particulates from engines. The filter material collects the particulates deep in the substrate (deep-bed filtration) before transitioning to other filtration methods on the surface. The deep-bed filtration has been characterized by modeling studies but little experimental information about the particulate, or soot, penetration in the filter material is available. Traditional evaluation methods do not provide sufficient contrast between the soot and mounting resins.

\section{Sample Preparation}

Due to the difficulty of locating carbon soot in the pores in these filters, ultra-thin section techniques (under 10-micron-thick sections) were used for the characterization of these samples. Under transmitted light, the carbon soot is black because it blocks the light, and the carbon in the resin material is relatively clear.

Samples were initially prepared by vacuum impregnating with a low viscosity thermosetting epoxy. The mounted samples were prepared using semi-automatic polishing machines in conjunction with grinding
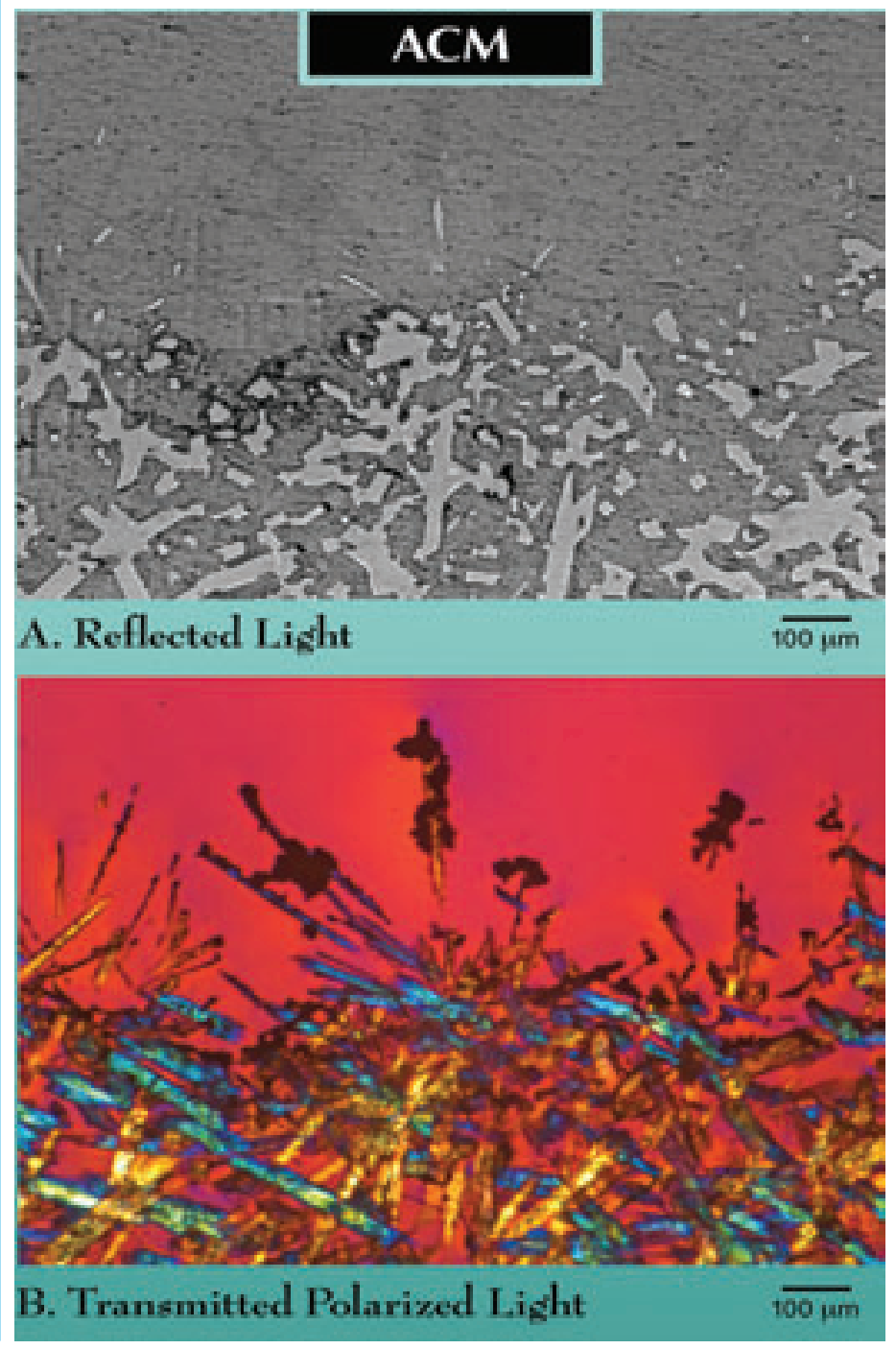

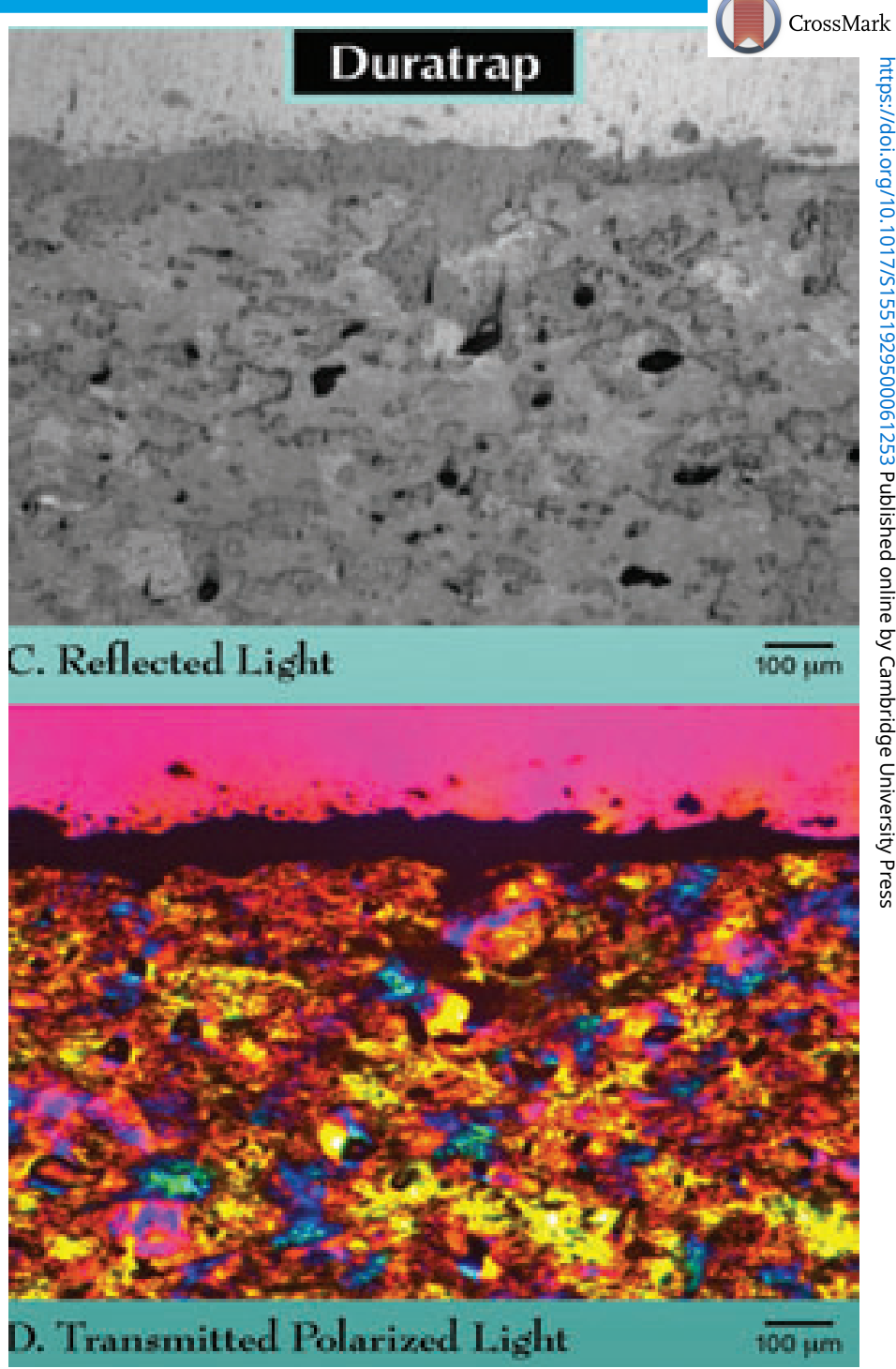

and polishing steps down to 1-micron diamond abrasive polish. After the mounted sample is polished, the mounted sample is sliced with a diamond saw to produce a thin wafer approximately $1-\mathrm{cm}$ thick, having a surface parallel to the originally polished surface. This thin wafer is then vacuum impregnated using epoxy resin and then mounting the polished side down contacting the petrographic glass side. The top or cut surface is then ground to approximately 20 microns using semiautomatic polishing machines and diamond abrasives, this is followed by vibratory polishing on a napless cloth and 1-micron diamond abrasive until the desired thickness is achieved.

\section{Results}

In this experiment, two types of substrate materials are examined using a thin section technique. An Advanced Ceramic Material (ACM) is shown in Figures A and B, with characteristic needle formations in the substrate and a more traditional Duratrap substrate is shown in Figures $\mathrm{C}$ and D. For the ACM the carbon soot capture (black) is shown on the edges of the needles (Figure $\mathrm{B}$ ) and also within the substrate. The Duratrap material shows the early formation of the surface soot layer on the top of the substrate and penetration of soot into the pores (Figure D).

\section{Conclusion}

By preparing the diesel filter using thin-sectioning techniques, researchers use transmitted light to distinguish the soot from the carbon in the mounting material. This procedure allows researchers to evaluate the efficacy of the diesel filters at a glance. 
Value and Excellence in SEMs

VEGA Scanning Electron Microscopes

Fully automated PC-controlled SEMs

designed for a multi-user environment.

High performance 4-lens optics provides

high resolution, high depth of focus,

extremely large field of view as well

as optimum working conditions

for any application.

High working vacuum and variable pressure operation up to $2000 \mathrm{~Pa}$.

Original patented Low Vacuum Secondary Detector for true secondary electron

imaging under low vacuum.

Full range of precision-engineered specimen chambers and stages.

Sophisticated yet easy-to-use software for microscope control

and image processing \&t evaluation.

Network operations with built-in remote control and diagnostics.

$3 \mathrm{D}$ surface reconstruction using 30 beam technology.
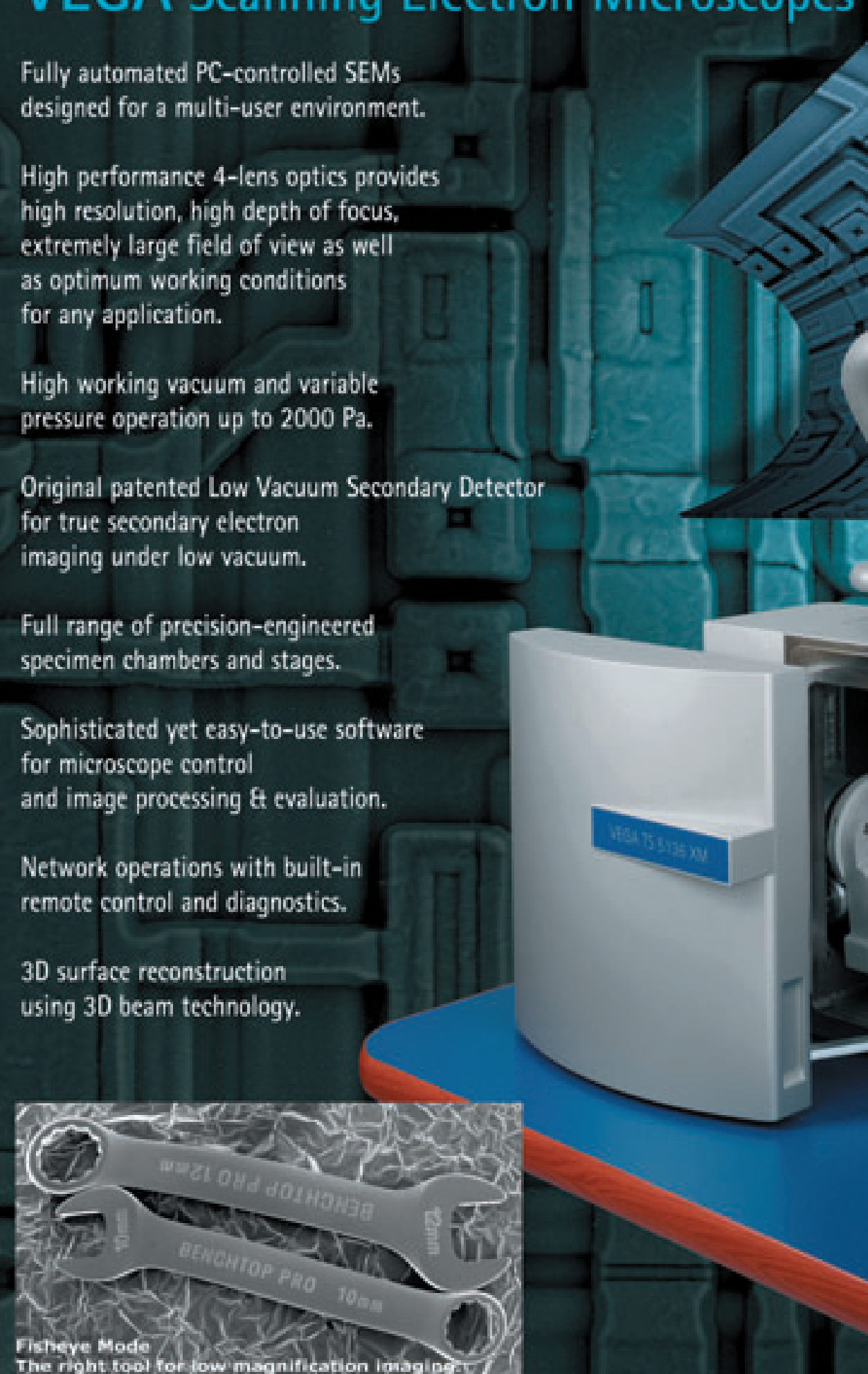

The right tool for jow magnification igragiperet f f

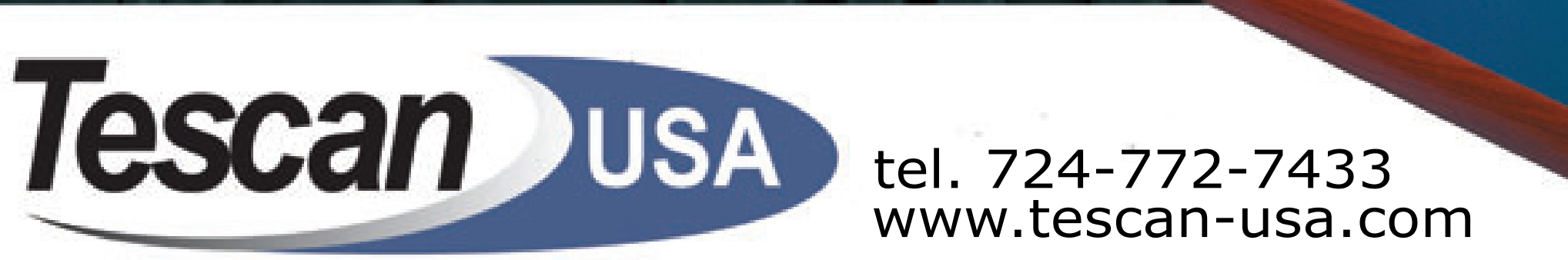

